\title{
SISTEM PAKAR DIAGNOSIS HAMA DAN PENYAKIT TANAMAN VANILI MENGGUNAKAN METODE CERTAINLY FACTOR
}

\author{
Cristovel Freeds Tosa, Ali Mahmudi, Joseph Dedy Irawan \\ Program Studi Teknik Informatika S1, Fakultas Teknologi Industri \\ Institut Teknologi Nasional Malang, Jalan Raya Karanglo km 2 Malang, Indonesia \\ fredstosa@gmail.com
}

\begin{abstract}
ABSTRAK
Vanili (Vanilla planifolia Andrews) merupakan salah satu tanaman yang mempunyai nilai ekonomi tinggi sebagai komoditas ekspor penghasil devisa yang masih potensial dikembangkan di Indonesia. Namun dalam perkembangannya di Indonesia terdapat beberapa kendala yang seringkali para petani vanili alami. Penyebab utamanya adalah kurangnya pengetahuan petani terhadap hama dan penyakit yang menyerang tanaman vanili. Oleh karena itu, dalam penelitian ini dibangun suatu sistem pakar diagnosis hama dan penyakit tanaman vanili berdasarkan pengetahuan yang diperoleh dari seorang pakar. Sistem pakar di bangun berdasarkan web menggunakan bahasa pemrograman PHP dan basis data MySql. Metode infersi yang digunakan adalah metode Certainly-Factor, dimana digunakan untuk menggambarkan tingkat keyakinan pakar terhadap suatu masalah. Data yang dibutuhkan untuk system pakar ini adalah data hama dan penyakit tanaman vanili beserta gejalagejalanya.

Dari hasil pengujian yang di lakukan terhadap 11 orang responden, yaitu 10 user dan 1 orang pakar, hasilnya $20 \%$ user sangat setuju, 56\% user setuju, $20 \%$ user kurang setuju, dan $4 \%$ user tidak setuju. Dan pada pengujian terhadap pakar hasilnya menunjukan $71.42 \%$ pakar setuju dan $28.58 \%$ kurang setuju.
\end{abstract}

\section{Kata Kunci : Sistem Pakar, Hama dan Penyakit Vanili, Certainly Factor}

\section{PENDAHULUAN}

\subsection{Latar Belakang}

Vanili (Vanilla planifolia Andrews) merupakan salah satu tanaman industri yang mempunyai nilai ekonomi tinggi sebagai komoditas ekspor penghasil devisa yang masih potensial dikembangkan di Indonesia. Namun dalam perkembangan vanili di Indonesia terdapat beberapa kendala yang sering dialami para petani vanili. Penyebab utamanya adalah kurangnya pengetahuan para petani terhadap hama dan penyakit yang menyerang tanaman vanili. Kerusakan tanaman vanili yang diakibatkan oleh serangan hama dan juga penyakit, akan menimbulkan dampak, dimana para petani vanili banyak yang mengalami gagal panen dan ada juga yang berhenti untuk bertani vanili kembali.

Sistem pakar adalah system berbasis computer yang menggunakan pengetahuan, fakta dan teknik penalaran dalam memecahkan masalah, yang biasanya hanya dapat diselesaikan oleh seorang pakar dibidang tertentu. Berdasarkan permasalahan, dapat di selesaikan dengan sebuah sistem pakar. Dengan sistem pakar akan lebih mudah mendiagnosis hama dan penyakit tanaman vanili karena memiliki kemampuan layaknya pakar dalam bidang pertanian. Pemanfaatan system pakar tanaman vanili dilakukan dengan menggunakan metode certainly factor, dimana digunakan pada jenis hama dan penyakit vanili.

Oleh karena itu, dikembangkannya suatu sistem pakar untuk mendiagnosis hama dan penyakit tanaman vanili mengunakan metode certainly factor berbasis web, sehingga dapat dapat diakses oleh para petani vanili secara online, dan dapat membantu para petani vanili agar dapat dengan mudah mendiagnosis hama dan penyakit tanaman vanili. Diharapkan juga sistem pakar ini dapat mengadopsi pengetahuan seorang pakar kedalam komputer sehingga masyarakat luas dapat menyelesaikan masalah layaknya seorang pakar.

\subsection{Rumusan Masalah}

Berdasarkan latar belakang, maka penulis merumuskan masalah yang akan dibahas sebagai berikut :

1. Bagaimana membuat system pakar untuk mendiagnosis hama dan penyakit pada tanaman vanili berbasis Website?

2. Bagaimana mendiagnosis hama dan penyakit menggunakan metode Certainly Factor?

\subsection{Batasan Masalah}

Dalam penyusunan skripsi agar menjadi sistematis dan mudah dimengerti, maka akan diterapkan beberapa batasan masalah, antara lain :

1. Data yang diambil pada penelitian ini, yaitu data jenis hama sejumlah 5 hama tanaman vanili dengan gejala hama sejumlah 7 gejala dan data jenis penyakit tanaman vanili sejumlah 5 penyakit dengan gejala penyakit sejumlah 13 gejala.

2. User pada aplikasi system pakar untuk diagnosis hama dan penyakit tanaman vanili adalah user (petani) dan admin (pakar). 


\subsection{Tujuan}

Adapun yang menjadi tujuan penulisan penelitian skripsi ini adalah sebagai berikut :

1. Aplikasi sistem pakar diagnosis hama dan penyakit tanaman vanili dibangun dengan menggunakan bahasa pemrograman $P H P$ dengan database $M y S Q L$, dan menghasilkan aplikasi sistem pakar berbasis web yang dapat membantu pengambilan keputusan berdasarkan hasil diagnosis hama dan penyakit tanaman vanili..

2. Untuk menentukan jenis hama dan penyakit pada tanaman vanili digunakan metode certainly factor.

\section{TINJAUAN PUSTAKA}

\subsection{Penelitian Terdahulu}

Penelitian ini dilakukan oleh Nanda di Jurusan Ilmu Komputer Fakultas Matematika dan Ilmu Pengetahuan Alam Universitas Lampung, Jurusan Budidaya Tanaman Perkebunan Politeknik Negeri Lampung, dan Kebun Percobaan LPTP Natar Lampung. Waktu penelitian dilaksanakan pada tahun ajaran 2018/2019. Pengambilan data dilakukan dengan dua tahap, yaitu studi literatur dan pengumpulan data. Tahapan pertama dilakukan pengumpulan data dari penelitian-penelitian sebelumnya yang sejenis, tahapan kedua adalah dengan berkonsultasi dengan pakar penyakit tanaman vanili. Dalam penelitian ini terdiri dari lima data penyakit, diantaranya: penyakit busuk batang, penyakit antranoksa, penyakit bercak coklat pada buah, penyakit busuk pangkal batang, dan penyakit karat merah. Penelitian menggunakan metode dempster shafer[1].

Penelitian ini dilaksanakan Rahmat Fauzi mulai bulan Mei 2005 dan berakhir bulan Agustus 2005 di rumah bibit $\mathrm{CV}$. CAKRA BUANA. Parameter pengamatan meliputi: Awal terjadi serangan (masa inkubasi), banyaknya tanaman terserang, prosentase vanili hidup, disklorasi, intensitas serangan, jumalah stek bertunas, jumlah daun, panjang tunas dan diameter tunas. Berdasarkan hasil penelitian dan pembahasan dapat disimpulkan, tidak terjadi interaksi antara macam ekstrak alami dan metode ekstraksi terhadap pengendalian penyakit Fusarium oxysporum pada stek tanaman panili (Vanilla planifolia L) [2].

Penelitian ini dilakukan oleh Victoria Henuhili sebagai materi penyuluhan pertanian di Desa Ngargosari Kec. Samigaluh Kulon Progo, untuk program mahasiswa KKN UNY pada tanggal 23 Agustus 2004. Penelitian ini menunjukan cara budidaya tanaman vanili, dengan memberikan pengetahuan mengenai faktor-faktor yang mempengaruhi pertumbuhan dan peningkatan kualitas produksi tanaman vanili. Dalam penelitian ini juga, penulis memberikan informasi mengenai lima data hama dan lima data penyakit tanaman vanili baserta gajala yang ditimbulkan[3].

Penelitian ini dilakukan oleh Ikorasaki yang berjudul "Sistem Pakar Mendiagnosa Penyakit Pada Tulang Dengan Menggunakan Metode Certainly Factor". Pada penelitian ini membuat suatu sistem pakar untuk diagnosis penyakit tulang. Penelitian ini bermula karena kesehatan tubuh manusia sangat bermasalah jika terjadi gangguan yang menyebabkan rasa sakit. Penyakit yang digunakan dalam penelitian ini adalah penyakit tulang. Dengan permasalahan tersebut Ikorasaki menggunakan Certainty Factor. Dengan menggunakan certainty factor dapat memberikan nilai kepstian dikarenakan dalam penganalisaan informasi dokter sering mengungkapkan dengan kata mungkin, kemungkinan besar, hampir pasti. Dari hasil penelitian tersebut bahwa diagnosis penyakit tulang ini dapat dijadikan alternatif bagi masyarakat untuk melakukkan diagnosis dini terhadap gejala-gejala penyakit tulang pada manusia[4].

Penelitian ini dilakukan oleh Mariana, Alan Wiedy, jurusan teknik informatika, fakultas teknik industri institut teknlogi nasional pada Maret 2019. Dalam penelitiannya yang berjudul "Sistem Pakar Diagnosis Penyakit Tanaman Semangka Menggunakan Metode Certainly-Factor", pada penelitian ini dibuat suatu sistem pakar untuk mendiagnosis penyakit tanaman semangka. Penelitian ini bermula karena permasalahan yang sering dialami oleh petani semangka, yang di akibatkan oleh serangan penyakit pada tanaman semangka. Dengan permasalahan tersebut, Mariana menggunakan metode certainly-factor untuk menggambarkan tingkat keyakinan pakar terhadap penyakit dan gejala penyakit tanaman semangka. Dari hasil penelitian tersebut dinyatakan bahwa diagnosis penyakit tanaman semangka dapat dijadikan alternatif bagi para petani semangka untuk melakukan diagnosis terhadap tanaman semangka berdasarkan gejalagejala yang dialami[5].

\subsection{Dasar Teori}

\subsubsection{Sistem Pakar}

System pakar adalah suatu program computer yang dirancang untuk mengambil keputusan yang diambil oleh seorang pakar. Dalam penyusunannya system pakar mengkombinasikan kaidah-kaidah penarikan kesimpulan dengan basis pengetahuan tertentu yang diberikan oleh satu orang pakar atau lebih, dalam bidang tertentu. Tujuan utama system pakar bukan untuk menggantikan kedudukan seorang pakar, tetapi hanya untuk memasyarakatkan pengetahuan dan pengalaman dari seorang pakar tesebut [6].

Berikut defenisi tentang system pakar menurut para ahli, antara lain:

1. Sistem pakar (expert system) secara umum adalah sistem yang berusaha mengadopsi pengetahuan manusia ke komputer, agar 
komputer dapat menyelesaikan masalah seperti yang biasa dilakukan oleh para ahli (Kusumadewi, 2003) [8].

2. Seorang pakar adalah orang yang mempunyai keahlian dalam bidang tertentu, yaitu pakar yang mempunyai knowledge atau kemampuan khusus yang orang lain tidak mengetahui atau mampu dalam bidang yang dimilikinya (Arhami, 2005) [9].

3. Sistem pakar adalah sistem berbasis komputer yang menggunakan pengetahuan, fakta, dan teknik penalaran dalam memecahkan masalah yang biasanya hanya dapat dipecahkan oleh seorang pakar dalam bidang tersebut (Kusrini, 2006) [10].

\subsubsection{Certainly Factor}

Merupakan metode yang digunakan untuk menyelesaikan kasus ketidakpastian, dimana ukurannya didasarkan pada suatu fakta atau ukuran yang biasanya digunakan oleh pakar. Seorang pakar, misalnya dokter menganalisis informasi yang ada dengan ungkapan seperti mungkin,kemungkinan besar pasti. Untuk mengamodasi hal ini kita menggunakan certainty factor guna menggambarkan tingkat keyakinan pakar terhadap masalah yang sedang dihadapi. [5]

Rumus certainty factor didefinisikan sebagaipersamaan berikut:

$\mathrm{CF}(\mathrm{H}, \mathrm{E})=\mathrm{MB}(\mathrm{H}, \mathrm{E})-\mathrm{MD}(\mathrm{H}, \mathrm{E})$

$\operatorname{MB}\left(h, 1^{\wedge} \mathrm{e} 2\right)=\operatorname{MB}(\mathrm{h}, \mathrm{e} 1)+\operatorname{MB}(\mathrm{h}, \mathrm{e} 2) *(1-\mathrm{MB}[\mathrm{h}, \mathrm{e} 1])$ $\operatorname{MD}\left(h, e^{\wedge} \mathrm{e} 2\right)=\operatorname{MD}(h, e 1)+\operatorname{MD}(h, e 2) *(1-M D[h, e 1])$

Keterangan :

$$
\begin{array}{ll}
\mathrm{H} & =\text { Hipotesis (dugaan) } \\
\mathrm{E} & =\text { Evidence }(\text { peristiwa atau fakta) }
\end{array}
$$

$\mathrm{CF}(\mathrm{H}, \mathrm{E})=$ certainty factor dari hipotesis $\mathrm{H}$ yang dipengaruhi oleh gejala (evidence) besarnya $\mathrm{CF}$ berkisar antara 0 sampai 1 . Nilai 0 menunjukkan ketidakpercayaan mutlak sedangkan nilai 1 menunjukkan kepecayaan mutlak.

$\mathrm{MB}(\mathrm{H}, \mathrm{E})=$ ukuran kenaikan kepercayaan (measure of increased belief) terhadap hipotesis $\mathrm{H}$ yang dipengaruhi oleh gejala $\mathrm{E}$.

$\mathrm{MD}(\mathrm{H}, \mathrm{E})=$ ukuran kenaikan ketidakpercayaan (measure of increased disbelief) terhadap hipotesisH yang dipengaruhi oleh gejala.

\subsection{3. $M y S Q L$}

$M y S Q L$ adalah salah satu jenis database server yang sangat terkenal. Kepopulerannya disebabkan MySQL menggunakan SQL sebagai bahan dasar untuk mengakses databasenya. Selain itu, MySQL bersifat free pada pelbagai paltform (kecuali pada windows, yang bersifat shareware atau perlu membayar setelah melakukan evaluasi dan memutuskan untuk digunakan dalam keleprluan produksi).
MySQL termasuk jenis RDBMS (Relational Database Management System). Itulah sebabnya istilah seperti tabel, baris, dan kolom digunakan pada MySQL [6].

\subsubsection{PhpMyAdmin}

PhpMyAdmin adalah sebuah software yang berbentuk seperti halaman situs yang terdapat pada web server. Fungsi dari halaman ini adalah sebagai pengendali database Mysql sehingga pengguna Mysql tidak perlu repot untuk menggunakan perintahperintah $S Q L$. Karena dengan adanya halaman ini semua hal tersebut dapat dilakukan dengan hanya meng-klik menu fungsi yang ada pada halaman PhpMyAdmin [6].

\section{METODE PENELITIAN}

\subsection{Analisis Sistem}

Merupakan suatu kegiatan yang menguraikan seluruh pokok masalah yang ada di dalamnya. Analisa merupakan tahapan awal sebelum masuk ke tahapan perancangan, sedangkan perancangan merupakan hasil dari keseluruhan analisa yang dapat memberikan solusi dalam suatu permasalahan.

\subsection{Kebutuhan Fungsional}

kebutuhan fungsional dalam perancangan sistem adalah sebagai berikut :

1. Website pada sistem pakar ini nantinya terdapat dua hak akses yang akan berinteraksi dengan sistem, yaitu Admin dan User.

2. Admin dapat mengolah data pada aplikasi dengan beberapa fitur yang nanti akan disediakan.

3. User dapat melakukan konsultasi dengan aplikasi sistem pakar ini dan melihat hasil konsultasinya.

4. admin meberikan cara penanggulanganya/cara mengatasi hama dan penyakit kepada user pada saat konsultasi berakir.

\subsection{Data Hama dan Penyakit}

Pada data hama dan panyakit digunakan sebagai input sistem pakar yang nantinya digunakan untuk mendiagnosis hama dan penyakit tanaman vanili.

\subsubsection{Tabel Hama dan Gejala 1. Tabel Hama}

Tabel 3.1 tabel hama vanili

\begin{tabular}{|l|l|l|}
\hline No & $\begin{array}{l}\text { Id } \\
\text { Hama }\end{array}$ & Hama \\
\hline 1 & h01 & Hama Bekicot \\
\hline 2 & h02 & $\begin{array}{l}\text { Hama Belalang Pedang } \\
\text { (Holoclora sp) }\end{array}$ \\
\hline 3 & h03 & Hama Penggerek Batang (larva) \\
\hline 4 & h04 & Hama Ulat Bulu \\
\hline 5 & h05 & Hama Kepiding (mertila sp) \\
\hline
\end{tabular}




\section{Tabel Gejala Hama}

Tabel 3.2 tabel gejala hama vanili

\begin{tabular}{|l|l|l|}
\hline No & $\begin{array}{l}\text { Id } \\
\text { Gejala }\end{array}$ & Gejala Hama \\
\hline 1 & gh01 & Merusak batang, bunga dan buah \\
\hline 2 & gh02 & $\begin{array}{l}\text { Merusak/memakan daun muda } \\
\text { dan batang panili }\end{array}$ \\
\hline 3 & gh03 & $\begin{array}{l}\text { Terdapat telur-telur di dalam } \\
\text { batang vanili }\end{array}$ \\
\hline 4 & gh04 & $\begin{array}{l}\text { Luka yang disebabkan oleh gigitan } \\
\text { hama dapat merupakan sarana } \\
\text { masuknya bibit penyakit }\end{array}$ \\
\hline 5 & gh05 & $\begin{array}{l}\text { Merusak/menggerek batang } \\
\text { tanaman panili yang menyebabkan } \\
\text { tanaman panili lambat laun layu } \\
\text { dan mati }\end{array}$ \\
\hline 6 & gh06 & $\begin{array}{l}\text { Merusak bagian pucuk, daun, } \\
\text { batang dan bunga }\end{array}$ \\
\hline 7 & gh07 & $\begin{array}{l}\text { Noda-noda pada daun, buah, } \\
\text { batang, akar, maupun kuntum } \\
\text { bunga }\end{array}$ \\
\hline
\end{tabular}

\section{Tabel Rule}

Tabel 3.3 Rule hama

\begin{tabular}{|l|l|l|l|l|l|l|}
\hline \multirow{2}{*}{ No } & Id & \multicolumn{3}{|l|}{ Id Hama } & \multicolumn{4}{l|}{} \\
\hline & Gejala & h01 & h02 & h03 & h04 & h05 \\
\hline 1 & gh01 & X & & & & \\
\hline 2 & gh02 & & X & & & \\
\hline 3 & gh03 & & X & & & \\
\hline 4 & gh04 & & X & & & \\
\hline 5 & gh05 & & & X & & \\
\hline 6 & gh06 & & & & X & \\
\hline 7 & gh07 & & & & & X \\
\hline
\end{tabular}

Dari tabel rule hama pada tanaman vanili diatas maka dapat dibentuk lima aturan (rule) analisis sebagai berikut:

a. Aturan 1 : IF gh01 THEN h01

b. Aturan 2 : IF gh02 AND gh03 AND gh04 THEN h02

c. Aturan $3: I F$ gh05 THEN h03

d. Aturan $4: I F$ gh06 THEN h04

e. Aturan $5:$ IF gh07 THEN h05

\section{Tabel Nilai MB, MD}

Tabel 3.4 nilai MB, MD

\begin{tabular}{|l|l|l|l|l|}
\hline No & $\begin{array}{l}\text { Id } \\
\text { hama }\end{array}$ & $\begin{array}{l}\text { Id } \\
\text { gejala }\end{array}$ & MB & MD \\
\hline 1 & h01 & gh01 & 0.6 & 0.4 \\
\hline 2 & h02 & gh02 & 0.6 & 0.4 \\
\cline { 3 - 5 } & & gh03 & 0.6 & 0.4 \\
\cline { 3 - 5 } & & gh04 & 0.8 & 0.2 \\
\hline 3 & h03 & gh05 & 0.2 & 0.8 \\
\hline 4 & h04 & gh06 & 0.6 & 0.4 \\
\hline 5 & h05 & gh07 & 0.8 & 0.2 \\
\hline
\end{tabular}

\subsubsection{Tabel Penyakit dan Gejala}

1. Tabel Penyakit

Tabel 3.5 tabel penyakit vanili

\begin{tabular}{|l|l|l|}
\hline No & $\begin{array}{l}\text { Id } \\
\text { Penyakit }\end{array}$ & Penyakit \\
\hline 1 & $\mathrm{p} 01$ & Penyakit busuk batang \\
\hline 2 & $\mathrm{p} 02$ & $\begin{array}{l}\text { Penyakit ganggang } \\
\text { (chephalevros henningsii) }\end{array}$ \\
\hline 3 & $\mathrm{p} 03$ & $\begin{array}{l}\text { Penyakit busuk pucuk dan } \\
\text { buah }\end{array}$ \\
\hline 4 & $\mathrm{p} 04$ & $\begin{array}{l}\text { Penyakit busuk pangkal } \\
\text { batang / penyakit busuk } \\
\text { Sclerotium (PBS) }\end{array}$ \\
\hline 5 & $\mathrm{p} 05$ & Penyakit antraknosa \\
\hline
\end{tabular}

\section{Tabel Gejala Penyakit}

Tabel 3.6 tabel gejala penyakit vanili

\begin{tabular}{|c|c|c|}
\hline No & $\begin{array}{l}\text { Id } \\
\text { Gejala }\end{array}$ & Gejala Penyakit \\
\hline 1 & gp01 & $\begin{array}{l}\text { Bagian batang yang teserang } \\
\text { penyakit mengeriput (mengisut) }\end{array}$ \\
\hline 2 & gp02 & $\begin{array}{l}\text { Bagian batang yang terserang } \\
\text { berubah menjadi cokelat, lalu } \\
\text { menghitam di sekeliling batang dan } \\
\text { akhirnya batang tersebut mati }\end{array}$ \\
\hline 3 & gp03 & $\begin{array}{l}\text { Bagian akar akan mati dan dalam } \\
\text { buah juga berubah warna menjadi } \\
\text { kecoklatan }\end{array}$ \\
\hline 4 & gp04 & $\begin{array}{l}\text { Perkembangbiakan akan berkurang } \\
\text { pada tanah yang masam }\end{array}$ \\
\hline 5 & gp05 & $\begin{array}{l}\text { Daun atau batang yaitu koloni } \\
\text { lumut yang berwarna hijau keabu- } \\
\text { abuan, kadang-kadang meluas } \\
\text { menutupi seluruh permukaan daun }\end{array}$ \\
\hline 6 & gp06 & $\begin{array}{l}\text { Pucuk yang terserang akan menjadi } \\
\text { busuk yang berwarna coklat } \\
\text { kekuningan, kemudian menjadi } \\
\text { hitam }\end{array}$ \\
\hline 7 & gp07 & $\begin{array}{l}\text { Banyak buah yang berguguran dan } \\
\text { bila menyerang tengah buah akan } \\
\text { hitam, kering selanjutnya mati }\end{array}$ \\
\hline 8 & gp08 & $\begin{array}{l}\text { Pangkal batang panili busuk } \\
\text { berwarna coklat muda }\end{array}$ \\
\hline 9 & gp09 & $\begin{array}{l}\text { Pada bagian tanaman yang } \\
\text { terserang dan tanah sekitarnya } \\
\text { seringkali terlihat miselium } \\
\text { berwarna putih atau sklerotia }\end{array}$ \\
\hline 10 & gp10 & $\begin{array}{l}\text { Serangan terbatas akar dan pangkal } \\
\text { batang panili sampai ketinggian } 5 \\
\text { cm dari permukaan tanah }\end{array}$ \\
\hline 11 & gp11 & $\begin{array}{l}\text { Bercak pada batang dan daun yang } \\
\text { telah tua }\end{array}$ \\
\hline 12 & gp12 & $\begin{array}{l}\text { Bercak dapat terjadi mulai dari tepi } \\
\text { daun dan bagian tengah. }\end{array}$ \\
\hline 13 & gp13 & $\begin{array}{l}\text { Bercak bervariasi dan berwarna } \\
\text { abuabu kemudian coklat } \\
\text { mengering }\end{array}$ \\
\hline
\end{tabular}




\section{Tabel Rule}

Tabel 3.7 Rule penyakit

\begin{tabular}{|c|c|c|c|c|c|c|}
\hline \multirow[t]{2}{*}{$\mathrm{No}$} & \multirow{2}{*}{$\begin{array}{l}\text { Id } \\
\text { Gejala }\end{array}$} & \multicolumn{5}{|c|}{ Id Penyakit } \\
\hline & & p01 & p02 & p03 & p04 & p05 \\
\hline 1 & gp01 & $\mathrm{X}$ & & & & \\
\hline 2 & gp02 & $\mathrm{X}$ & & & & \\
\hline 3 & gp03 & $\mathrm{X}$ & & & & \\
\hline 4 & gp04 & $\mathrm{X}$ & & & & \\
\hline 5 & gp05 & & $X$ & & & \\
\hline 6 & gp06 & & & $\mathrm{X}$ & & \\
\hline 7 & gp07 & & & $X$ & & \\
\hline 8 & gp08 & & & & $\mathrm{X}$ & \\
\hline 9 & gp09 & & & & $\mathrm{X}$ & \\
\hline 10 & gp10 & & & & $\mathrm{X}$ & \\
\hline 11 & gp11 & & & & & $\mathrm{X}$ \\
\hline 12 & gp12 & & & & & $X$ \\
\hline 13 & gp13 & & & & & $\mathrm{X}$ \\
\hline
\end{tabular}

Dari tabel rule penyakit pada tanaman vanili diatas maka dapat dibentuk lima aturan (rule) analisis sebagai berikut:

a. Aturan 1 : IF gp01 AND gp02 AND gp03 AND gp04 THEN p01

b. Aturan 2 : IF gp05 THEN p02

c. Aturan 3 : IF gp06 AND gp07 THEN p03

d. Aturan 4 : IF gp08 AND gp09 AND gp10 THEN p04

e. Aturan 5 : IF gp11 AND gp12 AND gp13 THEN p05

\section{Tabel Nilai MB, MD}

Tabel 3.8 nilai MB, MD

\begin{tabular}{|c|c|c|c|c|}
\hline No & $\begin{array}{l}\text { Id } \\
\text { penyakit }\end{array}$ & $\begin{array}{l}\text { Id } \\
\text { gejala }\end{array}$ & $\mathrm{MB}$ & $\mathrm{MD}$ \\
\hline \multirow[t]{4}{*}{1} & \multirow[t]{4}{*}{ p01 } & gp01 & 1 & 0 \\
\hline & & gp02 & 1 & 0 \\
\hline & & gp03 & 0.6 & 0.4 \\
\hline & & gp04 & 0.8 & 0.2 \\
\hline 2 & p02 & gp05 & 0.2 & 0.8 \\
\hline \multirow[t]{2}{*}{3} & \multirow[t]{2}{*}{ p03 } & gp06 & 0.8 & 0.2 \\
\hline & & gp07 & 0.4 & 0.6 \\
\hline \multirow[t]{3}{*}{4} & \multirow[t]{3}{*}{ p04 } & gp08 & 0.8 & 0.2 \\
\hline & & gp09 & 0.4 & 0.6 \\
\hline & & Gp10 & 0.8 & 0.2 \\
\hline \multirow[t]{3}{*}{5} & \multirow[t]{3}{*}{ p05 } & gp11 & 0.8 & 0.2 \\
\hline & & gp12 & 0.6 & 0.4 \\
\hline & & gp13 & 0.6 & 0.4 \\
\hline
\end{tabular}

\subsection{Struktur Menu}

Pada perancangan struktur menu terdapat dua struktur menu yang berkaitan, yaitu struktur menu Admin dan struktur menu User. Berikut merupakan rancangan struktur menu user, yang digunakan user untuk mengakses website. ditunjukan pada gambar 3.1

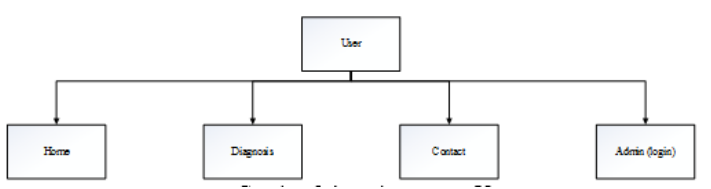

Gambar 3.1 struktur menu User

Pada gambar 3.1 struktur menu user terdapat menu Home, menu Diagnosis hama dan penyakit, menu contact, dan menu Admin untuk login. Disini user hanya dapat mengakses diagnosis Certainly Factor untuk gejala hama dan penyakit tanaman vanili.

Rancangan struktur menu Admin dapat dilihat pada gambar 3.2.

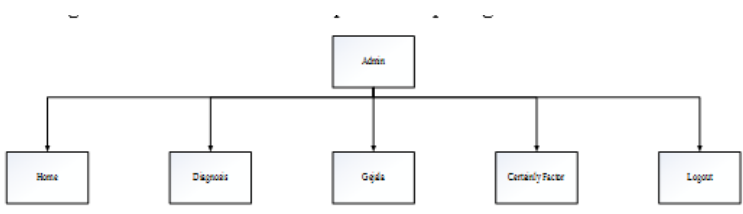

Gambar 3.2 struktur menu Admin

Pada gambar 3.2 struktur menu Admin terdapat menu Home, menu Diagnosis hama dan penyakit, menu Gejala hama dan penyakit, menu nilai Certainly Factor untuk hama dan penyakit serta menu Logout untuk admin. Digunakan admin untuk mengisi data hama dan penyakit tanaman vanili.

\subsection{Flowchart}

Flowchart adalah sekumpulan simbol-simbol yang menunjukan atau menggambarkan rangkaian kegiatan-kegiatan program dari awal hingga akhir, sehingga dapat diketahui bagaimana program berjalan dari dimulainya program hingga program itu selesai diproses.

\subsubsection{Flowchart user}

Alur rancagan flowchart user ditunjukan pada gambar 3.3 berikut. 


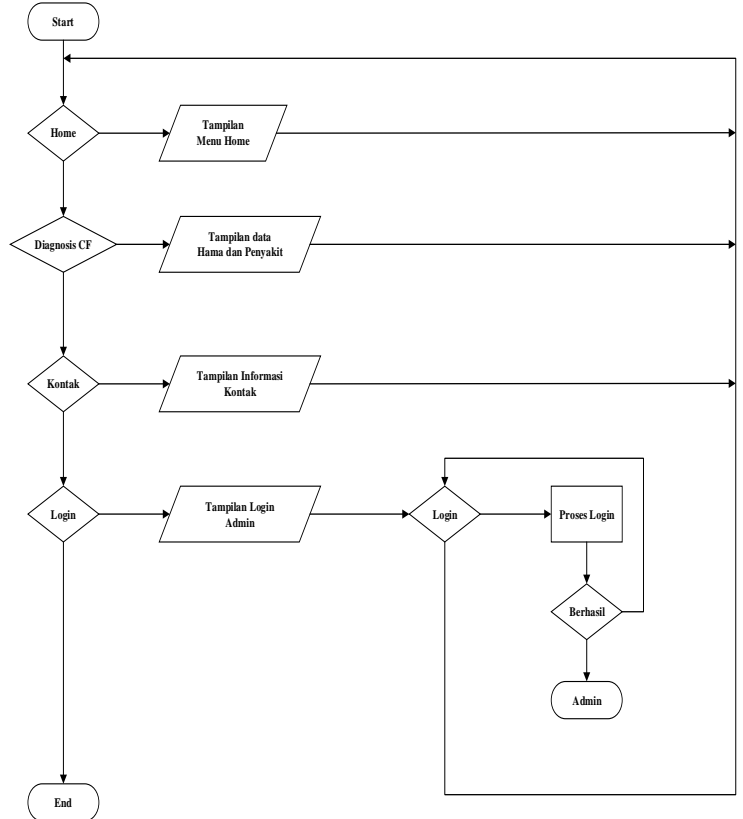

Gambar 3.3 Flowchart User

System ini diawali dengan halaman Home berisi ucapan selamat datang. Halaman Diagnosis berisikan tabel diagnosis gejala, yang nantinya user akan memilih gejala yang sudah ada lalu akan diproses menurut aturan dalam sistem yang sudah dibuat, setelah selesai diproses maka akan muncul informasi hasil diagnosis. Halaman Contact berisikan informasi pribadi admin. Halaman Admin berisikan form login untuk masuk ke sistemnya admin.

\subsubsection{Flowchart Admin}

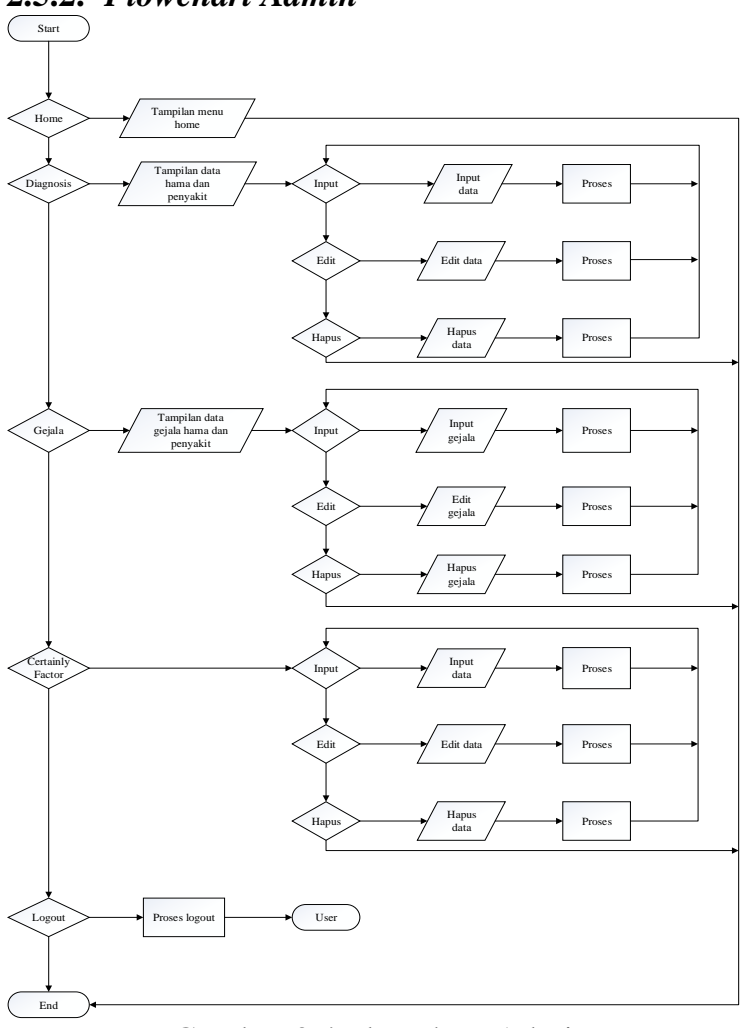

Gambar 3.4 Flowchart Admin
Setelah admin login dengan username dan password maka admin langsung masuk ke halaman Home admin. Setelah itu admin dapat langsung mengakses data, menambah data,edit data,hapus data pada halaman Dignosis dan Gejala. Kemudian halaman Certainty Factor untuk menambah dan memasukan nilai hama dan penyakit. Lalu ada halaman Admin untuk melakukan proses logout untuk kembali ke sistemnya user.

\section{HASIL DAN PEMBAHASAN}

\subsection{Implementasi}

Tahap implementasi merupakan tahap penerapan hasil perancangan sistem yang telah disusun sebelumnya menjadi suatu aplikasi yang siap untuk dijalankan. Implementasi pengembangan sistem pakar diagnosis hama dan penyakit pada tanaman vanili menggunakan metode certainty factor, sehingga memberikan kemudahan kepada user, dan pakar dalam menentukan hama dan penyakit tanaman vanili.

\subsubsection{Tampilan Halaman Konsultasi User}

Pada menu halaman konsultasi ini bertujuan untuk mengidentifikasi penyakit pada tanaman vanili, melalui pemilihan gejala.

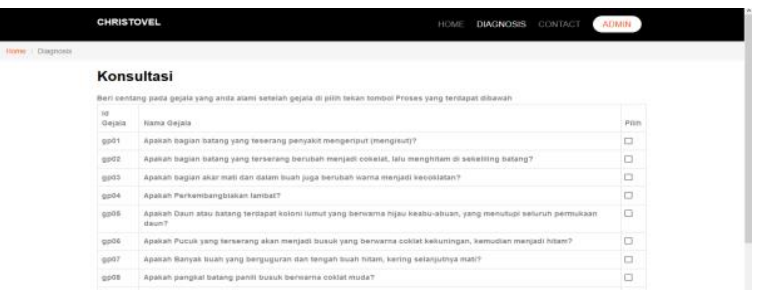

Gambar 4.1 tampilan halaman konsultasi penyakit

\subsubsection{Tampilan Hasil Konsultasi User} penyakit.

Tampilan untuk hasil dari diagnosis gejala

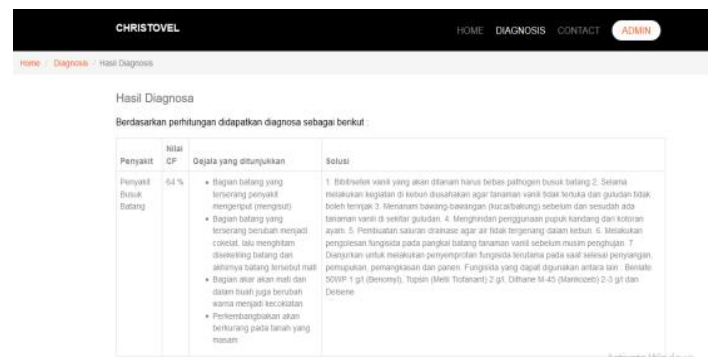

Gambar 4.2 tampilan hasil konsultasi penyakit

\subsubsection{Halaman Contact}

Halaman contact menampilkan informasi kontak dari admin yang mengelola website. Tampilan Kontak User 


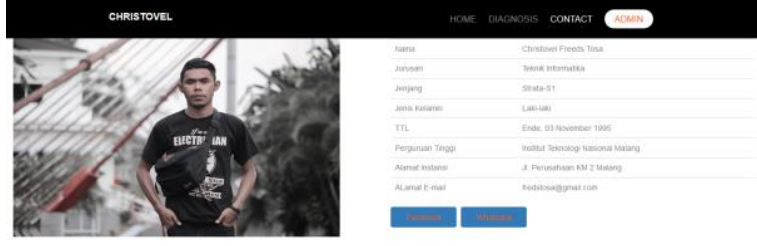

Gambar 4.3 tampilan menu Contact

\subsubsection{Halaman Admin (login)}

Pada halaman ini, admin memasukan username dan password untuk melakukan login ke website admin.

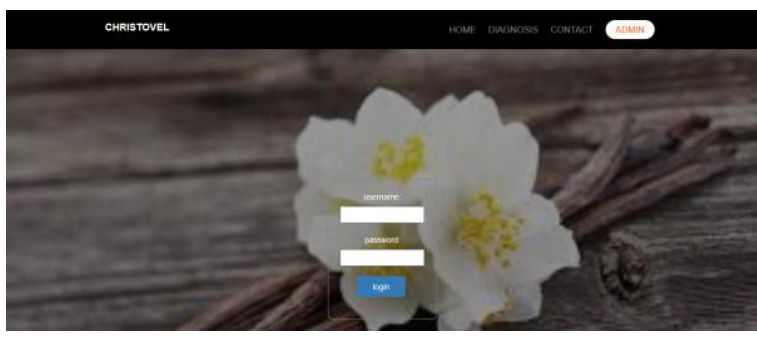

Gambar 4.4 tampilan menu login admin

\subsubsection{Halaman Data hama dan penyakit}

pada halaman ini, bertujuan agar admin dapat memasukan atau menambah data hama dan panyakit tanaman vanili

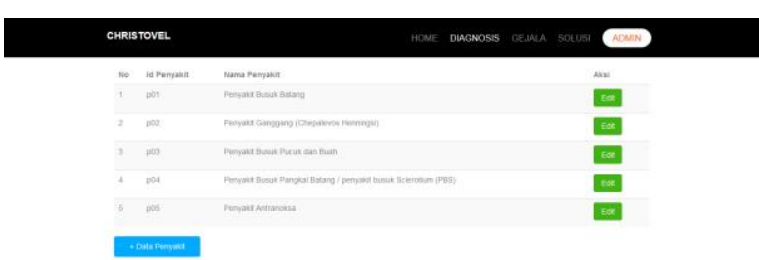

Gambar 4.5 tampilan halaman tambah data penyakit

\subsubsection{Halaman Data Gejala}

Halaman ini bertujuan agar admin dapat memasukan atau menambah data gejala hama dan penyakit tanaman vanili

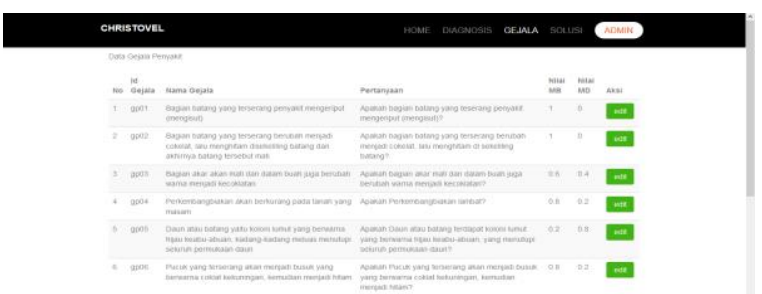

Gambar 4.6 tampilan halaman tambah data gejala penyakit

\subsection{Pengujian Fungsional Sistem}

Pengujian fungsionalitas sistem merupakan proses menampilkan sistem dengan maksud untuk menemukan adanya kesalahan atau tidak pada sistem sebelum sistem dipublikasikan agar nantinya dapat diambil kesimpulan apakah sistem berjalan dengan baik sesuai tujuan awal pembuatan. Hasil pengujian sistem ditunjukkan pada Tabel 4.1 sebagai berikut:
Tabel 4.1 fungsional sistem

\begin{tabular}{|l|l|l|l|l|}
\hline Akses & \multirow{2}{*}{ Fungsi } & \multicolumn{3}{|l|}{ Browser } \\
\hline & & MF & GC & IE \\
\hline Admin & Halaman login & $\sqrt{ }$ & $\sqrt{ }$ & $\sqrt{ }$ \\
\hline & $\begin{array}{l}\text { Tambah, edit, } \\
\text { hapus, dan simpan } \\
\text { data hama dan } \\
\text { penyakit }\end{array}$ & $\sqrt{ }$ & $\sqrt{ }$ & $\sqrt{ }$ \\
& $\begin{array}{l}\text { Tambah, edit, } \\
\text { hapus dan simpan } \\
\text { data gejala hama } \\
\text { dan penyakit }\end{array}$ & $\sqrt{ }$ & $\sqrt{ }$ & $\sqrt{ }$ \\
\hline & $\begin{array}{l}\text { Tambah, edit, } \\
\text { hapus, dan simpan } \\
\text { data solusi } \\
\text { pencegahan hama } \\
\text { dan penyakit }\end{array}$ & $\sqrt{ }$ & $\sqrt{ }$ & $\sqrt{ }$ \\
\hline & Halaman logout & $\sqrt{ }$ & $\sqrt{ }$ & $\sqrt{ }$ \\
\hline User & $\begin{array}{l}\text { Halaman menu } \\
\text { home }\end{array}$ & $\sqrt{ }$ & $\sqrt{ }$ & $\sqrt{ }$ \\
\hline & $\begin{array}{l}\text { Halaman proses } \\
\text { diagnosis dan } \\
\text { kosultasi }\end{array}$ & $\sqrt{ }$ & $\sqrt{ }$ & $\sqrt{ }$ \\
\hline & Halaman contact & $\sqrt{ }$ & $\sqrt{ }$ & $\sqrt{ }$ \\
\hline
\end{tabular}

Keterangan :

MZ = Mozila 60.0.1 (32-bit)

GC = Google Chrome Version 67.0.3396.99

IE $=$ Internet Explorer

$\sqrt{ }=$ Berhasil

$\mathrm{X} \quad=$ Tidak Berhasil

\section{KESIMPULAN DAN SARAN}

\subsection{Kesimpulan}

Berdasarkan permasalahan dan hasil pengujian yang telah dilakukan maka dapat di ambil beberapa kesimpulan antara lain :

1. Telah berhasil dibangun aplikasi system pakar untuk mendiagnosis hama dan penyakit tanaman vanili menggunakan metode certainly factor berbasis web, sistem ini dapat membantu pengguna diantaranya petani vanili untuk mendiagnosa hama dan penyakit pada tanaman vanli berdasarkan gejala-gejala yang muncul.

2. Sistem ini dapat memberikan informasi mengenai hama dan penyakit tanaman vanili, gejala yang timbul akibat serangan, dan solusi untuk pencegahan agar tidak terserang hama dan penyakit tanaman vanili.

3. Secara fungsional sistem ini dapat berjalan dengan baik dibeberapa web browser yaitu Mozila Firefox $=100 \%, \quad$ Chrome $=100 \%$, Internet Explorer $=100 \%$.

\subsection{Saran}

Adapun saran yang perlu dikembangkan kedepannya agar lebih baik untuk pengguna aplikasi diagnosis hama dan penyakit pada tanaman vanili menggunakan metode certainty factor ini adalah : 
1. Penambahan data gejala baru, penyakit baru, terkait penyakit tanaman vanili jika ada di kemudian hari.

2. Menambahkan form diskusi, sebagai media interaksi untuk pengunjung dan pakar.

3. Aplikasi ini dapat diimplementasikan dengan menggunakan android

\section{DAFTAR PUSTAKA}

[1] Nanda. (2019). SISTEM PAKAR DIAGNOSA PENYAKIT PADA TANAMAN VANILI MENGGUNAKAN METODE DEMPSTERSHAFER BERBASIS WEB

[2] Fauzi, Rahmat. (2007). PENGARUH PEMBERIAN MACAM EKSTRAK ALAMI DAN METODE EKSTRAKSI TERHDAP PENGENDALIAN PENYAKIT Fusarium oxysporum PADA STEK TANAMAN VANILI (Vanilla planifolia L.)

[3] Henuhili, Victoria. (2004). Budidaya Tanaman Vanili. Yogyakarta.

[4] Ikorasi,2015,'Sistem Pakar Mendiagnosa Penyakit Tulang Menggunakan Metode Certainty Factor',Seminar Nasional Informatika.

[5] Mariana, Alan Wiedy. (2019). SISTEM PAKAR DIAGNOSIS PENYAKIT TANAMAN SEMANGKA MENGGUNAKAN METODE CERTAINTY FACTOR. JATI (Jurnal Mahasiswa Teknik Informatika): Vol. 3 No. 1, Maret 2019.

[6] Bapu, Elvisiana. (2019). ANALISIS PERBANDINGAN METODE DEMPSTER SHAFER DAN CERTAINTY FACTOR PADA SISTEM PAKAR UNTUK DIAGNOSIS PENYAKIT DAN HAMA TANAMAN KAKAO. JATI (Jurnal Mahasiswa Teknik Informatika): Vol. 3 No. 1, Maret 2019
[7] Normawardah.(2019). SISTEM PAKAR DIAGNOSIS PENYAKIT TANAMAN JAGUNG MENGGUNAKAN METODE CERTAINTY FACTOR BERBASIS WEB. JATI (Jurnal Mahasiswa Teknik Informatika): Vol. 3 No. 1, Maret 2019

[8] Kusumadewi, S. (2003). Artificial Intelligence (Teknik dan Aplikasinya). Yogyakarta: Graha Ilmu

[9] Arhami, M. (2005). Konsep Dasar Sistem Pakar. Yogyakarta: Penerbit Andi.

[10] S.Kom, Kusrini. (2006), Sistem Pakar "Teori dan Aplikasinya", Penerbit Andi. Yogyakarta.

[11] Wahyu Agung Luhur Budianto, ST., Hafsah, S.Si, M.T dan Heru Cahya Rustamaji,S.Si,M.T. APLIKASI SISTEM PAKAR DIAGNOSA PENYAKIT DAN HAMA TANAMAN VANILI BERBASIS WEB.

[12] Kartikawati, Andriana, Rosihan Rohman. (2018). Sirkuler Informasi Tanaman Rempah dan Obat, Budidaya Vanili. Bogor: Balai Penelitian Tanaman Rempah Dan Obat

[13] Nurcahyani, Endang1, Issirep Sumardi2, Bambang Hadisutrisno3 \& E. Suharyanto 4. Maret (2012). PENEKANAN PERKEMBANGAN PENYAKIT BUSUK BATANG VANILI (FUSARIUM OXYSPORUM F.SP. VANILLAE) MELALUI

[14] SELEKSI ASAM FUSARAT SECARA IN VITRO

[15] Sudarma I. M. (2015). "Penyakit Tanaman Perkebunan: Kelapa, Kopi, Kakao, Panili, Cengkih, Tembakau, Karet, dan Jambu Mete". Penerbit Plantaxia. Yogyakarta:45-50.

[16] Pusat Data dan Informasi Pertanian. (2009)."Outlook Komoditas Perkebunan". Jakarta.

[17] Layanan Informasi Desa. (2018). "Penyakit Utama pada Tanaman Vanili. Jakarta. 